\title{
Genotype-phenotype relationship in 12 patients carrying cystic fibrosis mutation R334W
}

\author{
Guillermo Antiñolo, Salud Borrego, Miguel Gili, Javier Dapena, Inmaculada Alfageme, \\ Francisco Reina
}

Unidad de Fibrosis Quística, Hospital

Universitario "Virgen del Rocío", Sevilla, Spain

J Dapena

\section{Servicio de}

Gastroenterología, Hospital Universitario

"Virgen del Rocío", Sevilla, Spain

F Reina

\section{Servicio de}

Neumología, Hospital

Universitario de

Valme, Sevilla, Spain

I Alfageme

\section{Correspondence to:}

Dr Antiñolo.

Received 8 July 1996

Revised version accepted for

publication

4 September 1996 relation of gene defects and clinical expression

\begin{abstract}
Unidad de Genética Médica, Hospital Maternal, Hospital Universitario "Virgen del Rocío", Avda Manuel Siurot s/n, 41013 Sevilla, Spain G Antiñolo

S Borrego

Unidad de

Investigación, Hospital Universitario "Virgen del Rocío", Sevilla, Spain

M Gili

Abstract

We present a phenotype-genotype correlation analysis in 12 patients with cystic fibrosis (CF) carrying the mutation R334W in the CFTR gene. The clinical data obtained for this group were compared with the clinical data of $\Delta F 508$ I $\Delta$ F508 patients. Current age and age at diagnosis were significantly higher in the R334W mutation group $(p=0.028$ and $\mathrm{p}=0.0001$ ). We found a lower rate of Pseudomonas aeruginosa colonisation in patients carrying the $R 334 \mathrm{~W}$ mutation, although the difference was not found to be statistically significant. However, we found a statistically significant higher age of onset of Pseudomonas aeruginosa colonisation $(p=0.0036)$ in the group of patients with the R334W mutation. Thirty three percent of $R 334 \mathrm{~W}$ patients were pancreatic insufficient, significantly lower than the $\Delta F 508 / \Delta F 508$ patients $(p=0.004)$. We also found that the weight expressed as a percentage of ideal weight for height was significantly higher in patients with the R334W mutation $(\mathbf{p}=\mathbf{0 . 0 0 2 8})$.

( $F$ Med Genet 1997;34:89-91)
\end{abstract}

Keywords: cystic fibrosis; R334W mutation; genotypephenotype correlation.

Cystic fibrosis (CF) is an exocrine disorder predominantly affecting the pancreas, gut, lung, sweat ducts, and vas deferens. The cloning of the gene responsible for CF led to the identification of its product, the cystic fibrosis transmembrane conductance regulator (CFTR), and has led to the determination of the molecular defects of the gene ${ }^{1}$ and the corof $\mathrm{CF}^{2}$

The CFTR, a protein composed of 1480 amino acids, belongs to a family of $P$ glucoprotein membrane transport proteins, and acts as a phosphorylation regulated chloride channel. ${ }^{3-5}$ Since the CFTR gene was cloned, more than 400 mutations have been identified, the commonest being $\Delta F 508$. Mutation $\Delta F 508$ has a significant variation in prevalence among populations. ${ }^{6}$ In addition to $\Delta \mathrm{F} 508$, different nonsense, missense, splicing, and frameshift mutations have been identified (Cystic Fibrosis Analysis Consortium, CFGAC, personal communication).

Information about the clinical characteristics of specific genotypes may have significant implications for prognosis and patient care and is also important for genetic counselling.

We present an analysis of the phenotypegenotype correlation in 12 patients with the mutation R334W, an arginine to tryptophan change at codon 334 of the CFTR gene.

\section{Materials and methods}

PATIENTS

A total of 102 unrelated families originating from the south of Spain, with at least one affected person with a confirmed diagnosis of $\mathrm{CF}$, were included in this study. The diagnosis of CF was made on the basis of a chloride concentration $>60 \mathrm{mmol} / \mathrm{l}$. The clinical data collected were current age, sex, age at diagnosis, sweat test value, weight, height, weight expressed as a percentage of ideal weight for height, forced expiratory volume in one second (FEV1), forced vital capacity (FVC), ChrispinNorman score, presence of meconium ileus, presence of dehydration, Pseudomonas aeruginosa (PA) colonisation, age at PA colonisation, Schwachman score, and presence of other clinical complications.

\section{METHODS}

Genomic DNA was isolated from peripheral blood lymphocytes according to standard protocols. CFTR gene mutations were investigated as described elsewhere. ${ }^{78}$ Microsatellite haplotypes within the CFTR gene were studied in the patients and their parents as previously described. ${ }^{9}$ Sputum was considered positive if colonised by PA for more than six months/year. The sputum was washed and then homogenised in $2 \% \mathrm{~N}$-acylcysteine at $\mathrm{pH} 7.2$. Serial tenfold dilutions were prepared and inoculated onto blood agar, bile salt agar, phenylethyl agar (PEA), PEA with $0.5 \mu \mathrm{g} / \mathrm{ml}$ of penicillin, PEA with $4 \mu \mathrm{g} / \mathrm{ml}$ methicillin, and Levinthal's agar. Organisms were identified and enumerated by standard bacteriological methods. Patients were diagnosed as either pancreatic sufficient 
Table 1 Clinical characteristics of 12 patients with $R 334 \mathrm{~W}$ mutation

\begin{tabular}{|c|c|c|c|c|c|c|c|c|c|c|c|c|}
\hline & \multicolumn{12}{|l|}{ Patients } \\
\hline & 1 & 2 & 3 & 4 & 5 & 6 & 7 & 8 & 9 & 10 & 11 & 12 \\
\hline Genotype & $\begin{array}{l}\text { R334W/ } \\
\Delta \text { F508 }\end{array}$ & $\begin{array}{l}\mathrm{R} 334 \mathrm{~W} / \\
\Delta \mathrm{F} 508\end{array}$ & $\begin{array}{l}\mathrm{R} 334 \mathrm{~W} / \\
\Delta \mathrm{F} 508\end{array}$ & $\begin{array}{l}\mathrm{R} 334 \mathrm{~W} / \\
\Delta \mathrm{F} 508\end{array}$ & $\begin{array}{l}\mathrm{R} 334 \mathrm{~W} / \\
\Delta \mathrm{F} 508\end{array}$ & $\begin{array}{l}\mathrm{R} 334 \mathrm{~W} / \\
\Delta \mathrm{F} 508\end{array}$ & $\begin{array}{l}\text { R334W/ } \\
\text { G542X }\end{array}$ & $\begin{array}{l}\text { R334W/ } \\
\text { R1162X }\end{array}$ & $\begin{array}{l}\text { R334W/ } \\
\text { del84 }\end{array}$ & $\begin{array}{l}\text { R334W/ } \\
\text { G542X }\end{array}$ & $\begin{array}{l}\text { R334W/ } \\
\text { G542X }\end{array}$ & $\begin{array}{l}\text { R334W/ } \\
\text { G542X }\end{array}$ \\
\hline Sex & & $M$ & $\mathrm{~F}$ & $M$ & F & M & $\mathrm{F}$ & F & $\mathrm{F}$ & $\mathrm{F}$ & $\mathrm{F}$ & $\mathrm{F}$ \\
\hline Current age & 3 y $7 \mathrm{mth}$ & $27 y$ & 2 y $5 \mathrm{mth}$ & $25 \mathrm{y}$ & $17 \mathrm{y}$ & $59 \mathrm{y}$ & $\begin{array}{l}10 \text { y } 9 \\
\text { mth }\end{array}$ & $23 \mathrm{y}$ & 3 y 3 mth & $27 \mathrm{y}$ & $25 \mathrm{y}$ & $23 \mathrm{y}$ \\
\hline Age at diagnosis & $5 \mathrm{mth}$ & $15 \mathrm{y}$ & $5 \mathrm{mth}$ & $20 y$ & $2 y$ & $49 y$ & 5 y $6 \mathrm{mth}$ & $15 \mathrm{y}$ & $15 \mathrm{mth}$ & $25 \mathrm{y}$ & $24 \mathrm{y}$ & $21 \mathrm{y}$ \\
\hline $\begin{array}{l}\text { Age at first clinical } \\
\text { symptoms }\end{array}$ & $3 \mathrm{mth}$ & 1 y $4 \mathrm{mth}$ & $5 \mathrm{mth}$ & $4 y$ & $3 \mathrm{mth}$ & $35 \mathrm{y}$ & $8 \mathrm{y}$ & $1 \mathrm{y}$ & $4 \mathrm{mth}$ & $5 y$ & $17 \mathrm{y}$ & - \\
\hline $\begin{array}{l}\text { First clinical } \\
\text { symptoms }\end{array}$ & $\begin{array}{l}\text { Pulmonary/ } \\
\text { pancreatic }\end{array}$ & Pulmonary & Dehydration & Dehydration & Pulmonary & Pancreatic & Pulmonary & Dehydration & Dehydration & Pulmonary & Pulmonary & Asymptomatic \\
\hline Sweat $\mathrm{Cl}^{-} \mathrm{mEq} / \mathrm{l}$ & 90 & 90 & 80 & 100 & 105 & 110 & 110 & 100 & 85 & 100 & 100 & 100 \\
\hline Weight $^{\star}(\%)$ & 100 & 100 & 100 & 115 & 90 & 89 & 95 & 76 & 89 & 116 & 115 & 121 \\
\hline Chrispin-Norman & 4 & 20 & 2 & - & - & - & - & 23 & - & - & - & - \\
\hline Schwachman-Kulcycki & 90 & 65 & 100 & 95 & 65 & 70 & 95 & 50 & 95 & 85 & 90 & 95 \\
\hline FEV1 $\%$ predicted & - & 24 & - & 82 & 41 & 44 & - & 27 & - & 74 & 85 & 91 \\
\hline FVC $\%$ predicted & - & 43 & - & 91 & 51 & 60 & - & 43 & - & 82 & 84 & 97 \\
\hline $\begin{array}{l}\text { Lung colonisation } \\
\text { (LC) }\end{array}$ & No & Yes & No & No & Yes & Yes & No & Yes & No & No & No & No \\
\hline Age of onset of LC & - & $15 y$ & - & - & $17 \mathrm{y}$ & $58 \mathrm{y}$ & - & $14 \mathrm{y}$ & - & - & - & - \\
\hline Meconium ileus & No & No & No & No & Yes & No & No & No & No & No & No & No \\
\hline Dehydration & Yes & Yes & Yes & Yes & Yes & No & No & Yes & Yes & No & No & No \\
\hline $\begin{array}{l}\text { Pancreatic } \\
\text { insufficiency (PI) }\end{array}$ & Yes & Yes & No & No & No & Yes & No & No & No & No & Yes & No \\
\hline Age of onset of PI & $3 \mathrm{mth}$ & $26 y$ & - & - & - & $?$ & - & - & - & - & $24 \mathrm{y}$ & - \\
\hline Sterility & - & Yes & - & Yes & - & Yes & - & - & - & No & No & No \\
\hline
\end{tabular}

* Weight expressed as a percentage of ideal weight for height.

or insufficient on the basis of fecal fat balance studies according to the method of Van der Kamer et al. ${ }^{10}$

STATISTICAL ANALYSIS

The difference in mean values between the groups was analysed by Student's unpaired $t$ test (two tailed) or Newman-Keules $t$ test (for unequal variances) for continuous variables with normal distribution, and by the MannWhitney test for continuous variables with non-normal distribution. Categorical variables were analysed by the chi-square test or Fisher's exact test. All statistical analyses were performed with BMPD Dynamic statistical software. ${ }^{11}$

\section{Results}

The 12 patients with $\mathrm{R} 334 \mathrm{~W}$ originated from Andalusia (south of Spain). Six patients were compound heterozygotes for R334W and $\Delta F 508$, four for R334W and G542X, one for R334W and 1949del84, and one for R334W and R1162X. All the R334W chromosomes showed the intragenic microsatellite haplotype 17-46-13 (IVS8CA-IVS17BTA-IVS17BCA).
Detailed clinical data for these 12 patients are shown in table 1 . The clinical data for these 12 patients were compared with those of 28 $\Delta F 508$ homozygous patients (table 2). Patients 10,11 , and 12 are sisters.

No significant differences were found when comparing sweat test values, presence of meconium ileus, dehydration, lung function, and Shwachman score. The current age and age at diagnosis were significantly higher in the R334W mutation group ( $p=0.028$ and $\mathrm{p}=0.0001$, respectively). A lower rate of PA colonisation was found in the group of patients with the R334W mutation, although the difference was not statistically significant. However, a statistically significant higher age of onset of PA colonisation $(p=0.0036)$ was found in the group of patients with the R334W mutation. Thirty three percent of $\mathrm{R} 334 \mathrm{~W}$ patients were pancreatic insufficient, a figure significantly lower than the $\Delta \mathrm{F} 508 / \Delta \mathrm{F} 508$ patients $(p=0.004)$. We also found that the weight expressed as a percentage of ideal weight for height was significantly higher in patients with the R334W mutation $(\mathrm{p}=0.0028)$.

Table 2 Clinical characteristics of 12 patients with R334W mutation, compared to $\Delta F 508 / \Delta F 508$ patients

\begin{tabular}{|c|c|c|c|}
\hline & \multicolumn{3}{|l|}{ Genotype } \\
\hline & $\Delta F 508 / \triangle F 508(n=28)$ & $R 334 W(n=12)$ & \\
\hline & Mean (SD) & & \\
\hline Current age & $9.6(6.0)$ & $20.4(15.6)$ & $p=0.028$ \\
\hline Age at diagnosis & $2.4(3.3)$ & $14.7(14.6)$ & $\mathrm{p}=0.0001$ \\
\hline Sweat test & $99.4(6.4)$ & $95.8(9.0)$ & NS \\
\hline FEV1 $\%$ predicted & $54.1(21.6)$ & $58.5(27.4)$ & NS \\
\hline FVC $\%$ predicted & $59.9(17.3)$ & $68.9(22.1)$ & NS \\
\hline Weight ${ }^{\star}$ & $0.9(0.06)$ & $1.0(0.1)$ & $p=0.0028$ \\
\hline Chrispin-Norman & $7.9(4.3)$ & $9.2(5.1)$ & NS \\
\hline Age of onset of LC & $7.1(4.8)$ & $26.0(21.4)$ & $\mathrm{p}=0.0036$ \\
\hline Age of onset of PI & $0.3(1.2)$ & $24.8(20.0)$ & \\
\hline Meconium ileus & $3 / 28(10.7)$ & $1 / 12$ & NS \\
\hline Dehydration & $9 / 28(32.1)$ & $7 / 12(58.3)$ & NS \\
\hline Pancreatic insufficiency & $28 / 28(100.0)$ & $4 / 12(33.3)$ & $p=0.004$ \\
\hline Lung colonisation & $17 / 28(60.7)$ & $4 / 12$ & NS \\
\hline
\end{tabular}

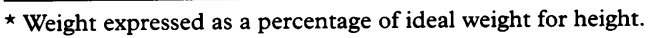




\section{Discussion}

The R334W mutation of the CFTR gene is a missense mutation, first identified in $1991,{ }^{7}$ that corresponds to the substitution of an arginine by a tryptophan at position 334 in exon 7 of the CFTR gene. R334W is a class IV (defective conductance) mutation. ${ }^{12}$ Class IV mutations (for example, R117H, R334W, and $\mathrm{R} 347 \mathrm{P}$ ) occur in the membrane spanning domains and are predicted to cause a mild CF phenotype. ${ }^{12}$

The R334W mutation has been described in a number of patients in different populations, although the worldwide prevalence is less than $0.1 \%$. In our CF patients, $\mathrm{R} 334 \mathrm{~W}$ has a prevalence of $4.9 \%$ (10/204 CF chromosomes). The association of intragenic microsatellite haplotypes 17-46-13 (IVS8CA-IVS17BTAIVS17BCA) with the different R334W chromosomes points to a single origin in the Spanish families described previously. ${ }^{13}$

Our results provide new data to support that patients with the R334W mutation suffer less severe expression of the disease and that the disease can be diagnosed later, as reported by Estivill et al. ${ }^{14}$ The proportion of pancreatic insufficient patients with the R334W mutation in our study is lower (33\%) when compared to the proportion of pancreatic insufficient patients in the paper by Estivill et $a l^{14}(60 \%)$. In our study the number of pancreatic sufficient patients with $\mathrm{R} 334 \mathrm{~W}$ varied according to the age at which pancreatic status was assessed, the later the age the smaller the number of pancreatic sufficient patients, with most patients being pancreatic sufficient at 20 years of age. It may suggest that pancreatic function in this group of patients declines with age. This fact is supported by the pancreatic status found in patients 10,11 , and 12 , belonging to the same family. While patients 10 and 12 are at the lower limit of pancreatic sufficiency, patient 11 has minimal pancreatic insufficiency.

Chronic infection with PA is the main cause of morbidity and mortality in CF patients. We did not find statistically significant differences with regard to lung colonisation by this pathogenic bacteria, although a lower rate of colonisation was found in R334W patients. A slightly higher proportion of lung colonisation in R334W patients compared to $\Delta \mathrm{F} 508 / \Delta \mathrm{F} 508$ patients has previously been reported, ${ }^{14}$ although the lung colonisation was referred to as bacterial pathogens in that report. On the other hand, a significant higher age at colonisation was found in our group of patients suggesting that R334W may be a lower risk allele than $\Delta \mathrm{F} 508$ for the acquisition of PA.

Interfamilial and intrafamilial clinical diversity for pancreatic insufficiency and the variation in pulmonary disease indicates that other factors, either genetic or environmental, must affect the severity and progression of the disease. In fact, it has been recently shown that the severity of CF in mice can be modified by at least one unlinked genetic locus. ${ }^{15}$ Environmental factors, such as age at diagnosis, a previous affected sib, medical care, or degree of compliance with treatment regimens, may further contribute to the variatiation of the clinical spectrum of the disease in CF patients.

1 Kerem BS, Rommens JM, Buchanan JA, et al. Identification of the cystic fibrosis gene: genetic analysis. Science of the cystic fib

2 Kerem E, Corey M, Kerem BS, et al. The relation between genotype and phenotype in cystic fibrosis: analysis of the most common mutation ( $\triangle \mathrm{F} 508)$. N Engl F Med 1990;323: 1517-22.

3 Dalemans W, Barbry P, Champigny G, et al. Altered chloride ion channel kinetics associated with the $\Delta \mathrm{F} 508$ cystic fibrosis mutation. Nature 1991;354:526-8.

4 Rommens JM, Dho S, Bear CE, et al. cAMP-inducible chloride conductance in mouse fibroblast line stably expressing the human cystic fibrosis transmembrane conductance the human cystic fibrosis transmembrane conduct

5 Bear EC, Li C, Karner N, et al. Purification and functional Bear EC, Li C, Karner N, et al. Purification and functional
reconstitution of the cystic fibrosis transmembrane conreconstitution of the cystic fibrosis transmembrane
ductance regulator (CFTR). Cell 1992;68:809-18.

6 The Cystic Fibrosis Analysis Consortium. Population variation of common CF mutations. Hum Mutat 1994;4:16777

7 Gasparini P, Nunes V, Savoia A, et al. The search for south European cystic fibrosis mutations: identification of two new mutations, four variants and intronic sequences. Genomics 1991;10:193-200.

8 Borrego S, Casals T, Dapena J, et al. Molecular and clinical analyses of cystic fibrosis in the south of Spain. Clin Genet analyses of cystic

9 Morral N, Estivill X. Multiplex PCR amplification of three microsatellites within the CFTR gene. Genomics 1992;13: 1362-4

10 Van der Kamer JH, ten Bokkel Huinink H, Weyers HA. Rapid method for the determination of fat in faeces. $\mathcal{F}$ Biol Chem 1949;117:347-55.

11 BMDP Statistical Software Manual (2 volumes). Berkeley: University of California Press, 1994.

12 Welsh MJ, Smith AE. Molecular mechanisms of CFTR chloride channel dysfunction in cystic fibrosis. Cell chloride channel

13 Morral N, Llevadot R, Casals T, et al. Independent origins of cystic fibrosis mutations R334W, R347P, R1162X, and $3849+10 \mathrm{kbCT}$ provide evidence of mutation recurrence in the CFTR gene. Am $\mathcal{F}$ Hum Genet 1994;55:890-8.

14 Estivill X, Ortigosa L, Pérez-Frías J, et al. Clinical characteristics of 16 cystic fibrosis patients with the missense mutation R334W, a pancreatic insufficiency mutation with variable age of onset and interfamilial clinical differences. Hum Genet 1995;95:331-6.

15 Rozmahel R, Wilchansk M, Matin A, et al. Modulation of disease severity in cystic fibrosis transmembrane conductance regulator deficient mice by a secondary genetic factor. Nat Genet 1996;12:280-7. 